\title{
Gastrointestinal Motility, Mucosal Mast Cell, and Intestinal Histology in Rats: Effect of Prednisone
}

\author{
Maysa Bruno de Lima, ${ }^{1}$ Loyane Almeida Gama, ${ }^{2}$ \\ Andrieli Taise Hauschildt, ${ }^{1}$ Denize Jussara Rupolo Dall'Agnol, ${ }^{2}$ \\ Luciana Aparecida Corá, ${ }^{3}$ and Madileine Francely Americo ${ }^{1}$ \\ ${ }^{1}$ Federal University of Mato Grosso, UFMT, Barra do Garças, MT, Brazil \\ ${ }^{2}$ São Paulo State University, UNESP, Botucatu, SP, Brazil \\ ${ }^{3}$ Alagoas State University of Health Sciences, UNCISAL, Maceio, AL, Brazil \\ Correspondence should be addressed to Luciana Aparecida Corá; lacora@pq.cnpq.br
}

Maysa Bruno de Lima and Loyane Almeida Gama contributed equally to this work.

Received 29 April 2017; Revised 20 July 2017; Accepted 13 August 2017; Published 19 September 2017

Academic Editor: Viness Pillay

Copyright (C) 2017 Maysa Bruno de Lima et al. This is an open access article distributed under the Creative Commons Attribution License, which permits unrestricted use, distribution, and reproduction in any medium, provided the original work is properly cited.

Our aim was to verify the effects of prednisone related to gastrointestinal motility, intestinal histology, and mucosal mast cells in rats. Two-month-old male Wistar rats were randomly assigned to control group (vehicle) animals receiving saline $0.9 \%(n=$ 7) or treated orally with $0.625 \mathrm{mg} / \mathrm{kg} /$ day of prednisone $(n=7)$ or $2.5 \mathrm{mg} / \mathrm{kg} /$ day of prednisone $(n=7)$ during 15 days. Mast cells and other histologic analyses were performed in order to correlate to gastric emptying, cecum arrival, and small intestine transit evaluated by Alternating Current Biosusceptometry. Results showed that prednisone in adult rats increased the frequency of gastric contractions, hastened gastric emptying, slowed small intestinal transit, and reduced mucosal mast cells. Histologically, the treatment with both doses of prednisone decreased villus height, whereas longitudinal and circular muscles and crypt depth were not affected. These findings indicate an impairment of intestinal absorption which may be linked to several GI dysfunctions and symptoms. The relationship between gastrointestinal motor disorders and cellular immunity needs to be clarified in experimental studies since prednisone is one of the most prescribed glucocorticoids worldwide.

\section{Introduction}

Glucocorticoids and their derivatives are the most prescribed synthetic drugs in clinical practice due to their large immunomodulatory activity [1]. Over the last 20 years, more than $30 \%$ of the general population in the US and in the UK received systemic glucocorticoid therapy [2-4]. In this scenario, prednisone stands out in the treatment of numerous inflammatory and autoimmune diseases, and as a part of immunosuppressive regimens after transplantation $[3,5]$. Even though the efficacy of glucocorticoids is indisputable, they are associated with several adverse effects linked to long term use and/or high dose administration $[1,4]$. Recent studies indicate that, in contrast with long term use, complications regarding short term use are much less understood, and data is insufficient to attend clinical practice guidelines [6]. However, studies towards evaluating side effects of prednisone on the gastrointestinal (GI) tract are controversial, although absorption surface, cellular transport, motility, and $\mathrm{pH}$ may modify its pharmacokinetics [7].

For several gastrointestinal diseases, the role of the mucosal immunity is currently being explored [8]. Due to its anti-inflammatory and immunosuppressive activities, prednisone can induce suppression in the subpopulation of immune cells in the intestinal mucosa [9]. Intestinal mast cells (MC) have an important role in host defense against microbes, mucosal regulatory functions, epithelial cells secretions, and smooth muscle contraction and peristalsis [10]. Also, chemical mediators released by activated mast cells can interact with enteric neurons and trigger physiological 
changes in GI tract, contributing to visceral hypersensitivity and dysmotility [11].

Adverse effects of prednisone are well-documented for several systems and/or for specific diseases. In mice pulmonary tissue, treatment with prednisone was able to reduce the mucosal mast cell transendothelial migration [12]. However, the effects of prednisone on GI histophysiological parameters and motility had not yet been documented or even neglected. In this context, novel studies could offer additional insights into normal physiology and the alterations caused by short term use of prednisone.

Noninvasive techniques such as Alternating Current Biosusceptometry (ACB) are essential to evaluate GI motor functions, including gastric contractility [13], gastric emptying, and intestinal transit [14] in physiological conditions expressing more accurate results $[14,15]$. New and harmless studies focusing on the relationships between the immune system, intestinal mucosa, and motility contribute towards increasing the knowledge to support the short term use of glucocorticoids for treatment of gastrointestinal diseases [1, 16]. Hence, the aim of this study was to investigate the effects of prednisone regarding gastrointestinal motility, intestinal histology, and mucosal mast cells in rats.

\section{Materials and Methods}

2.1. Animals and Experimental Groups. Male Wistar rats (250-300 g) were maintained in controlled conditions of temperature $\left(22 \pm 3^{\circ} \mathrm{C}\right)$, humidity $(60 \pm 5 \%)$, and 12-hour light/dark cycle with access to commercial chow (Purina ${ }^{\circledR}$ ) and filtered water ad libitum. All experimental procedures were approved by the Ethics Committee on Animal Research from Federal University of Mato Grosso (protocol number 23108.049862/13-3) and followed the Guidelines for Ethical Conduct in the Care and Use of Experimental Animals.

Animals were randomly assigned to control group, in which animals received only vehicle $(0.9 \% \mathrm{NaCl})(n=7)$, and treated group, in which animals received $0.625 \mathrm{mg} / \mathrm{kg} /$ day of prednisone $(n=7)$ or $2.5 \mathrm{mg} / \mathrm{kg} /$ day of prednisone $(n=7)$. Vehicle or prednisone treatments were administered orally during 15 consecutive days, always at the same time period. All analysis were performed at the end of the administration of vehicle or prednisone.

2.2. Alternating Current Biosusceptometry (ACB). Magnetic monitoring of GI transit and contractility was performed employing the ACB technique (Br4-Science ${ }^{\circledR}$, Brazil) $[13,14]$. ACB sensor measures the magnetic flux variation between excitation and detection coils through lock-in amplifiers. Signals generated by magnetic materials in response to an applied magnetic field are detected and the signal intensity depends on the amount of magnetic material and the distance between the sensor and sample. In this study, ferrite powder $\left(\mathrm{MgZnFe}_{2} \mathrm{O}_{3}\right.$, Imag, Brazil) was used as a nonabsorbable magnetic marker incorporated to laboratory chow. Detailed technical information has been reported earlier [13, 15].

2.3. Gastrointestinal Transit. After fasting overnight, animals were fed with the magnetically marked chow (1.6 g laboratory chow blended with $0.4 \mathrm{~g}$ ferrite powder). ACB sensor was placed on the abdominal surface and the maximum magnetic signal intensity value for both stomach and cecum projection (based on anatomical references) was recorded. Subsequent measurements were performed in awake rats upon those same points at regular 15-min intervals for at least $5 \mathrm{~h}$ [14].

2.4. Gastric Contractility. For GI transit measurements, the animals were anesthetized with $75 \mathrm{mg} / \mathrm{kg}$ ketamine (Cetamin ${ }^{\circledR}$, Syntec, Brazil) plus $2.5 \mathrm{mg} / \mathrm{kg}$ acepromazine (Acepran ${ }^{\circledR}$ Vetnil, Brazil), intraperitoneally. Animals were then laid in supine and the ACB sensor was placed on the stomach surface towards recording the magnetic signals continuously for 30 minutes at a sampling rate of $20 \mathrm{~Hz}$, by using a multichannel recorder (MP100 System; BIOPAC, Santa Barbara, CA, USA) [13].

2.5. Sample Collection. After gastric contractility measurements, animals were killed by anesthetic overdose consisting of $240 \mathrm{mg} / \mathrm{kg}$ ketamine plus $45 \mathrm{mg} / \mathrm{kg}$ xylazine chlorhydrate solution (Xilazin ${ }^{\circledR}$, Syntec, Brazil) administered intraperitoneally. Immediately after the anesthetic overdose, the animals were decapitated in order to collect blood and tissues for analysis.

2.6. Blood Cell Count. Blood cell count for both control and treated animals groups was carried out by two different methods. Firstly, to analyze the total number of leukocytes, blood samples collected in EDTA-coated tube were diluted 1:20 in Turk solution, counted using a Neubauer chamber, and the results were expressed in $10^{3} / \mathrm{mm}^{3}$. Secondly, to differential cell counts, a total of 100 cells were obtained using a blood smear, and the slides were stained with panoptic (Instan-prov, Neuprov ${ }^{\circledR}$ ). Cell populations were differentially counted based on the morphological features and the results were presented in absolute values $\left(10^{3} / \mathrm{mm}^{3}\right)$ [17].

2.7. Histological Analysis. Tissue samples from duodenum were fixed in methacarn (60\% methanol, 30\% chloroform, and $10 \%$ glacial acetic acid), dehydrated in alcohol series, cleared in xylene, and embedded in paraffin. Semiserial 4 micrometers $(\mu \mathrm{m})$ sections (microtome HM-355S Automatic Microtomes Thermo Scientific) were stained with toluidine blue $0.5 \%$ and hematoxylin and eosin (HE). Toluidine blue $0.5 \%$ staining sections were used to identify mast cells (MC) in the intestinal mucosa, since MC granules display metachromatic staining after uptake of toluidine blue dye. For each rat, sections of duodenum were randomly selected. Twenty well-oriented villus-crypt units (VCU) were examined per animal and expressed as mucosal MC per VCU [18]. HE staining was used to morphometric measurement of villus height, crypt depth, and thickness of the circular and longitudinal muscle layers. Images were captured on an optical microscope (Zeiss, Germany) coupled to a highresolution camera (AxioCam ERc5s, Zeiss, Germany) and analyzed using the ZEN Blue Software 2011 (Zeiss, Germany) [19]. Analyses concerning MC mucosal number and morphometric measurement were blinded to avoid bias. 
TABLE 1: Total leukocytes and differential cell counts after vehicle or prednisone treated rats with $0.625 \mathrm{mg} / \mathrm{Kg} / \mathrm{day}$ and $2.5 \mathrm{mg} / \mathrm{Kg} / \mathrm{day}$, respectively.

\begin{tabular}{lccc}
\hline & Vehicle & $0.625 \mathrm{mg} / \mathrm{Kg}$ & $2.5 \mathrm{mg} / \mathrm{Kg}$ \\
\hline Total leukocytes & $4.41 \pm 0.26$ & $2.43 \pm 0.32^{*}$ & $2.49 \pm 0.06^{*}$ \\
Lymphocytes & $2.83 \pm 0.11$ & $1.37 \pm 0.36^{*}$ & $1.37 \pm 0.27^{*}$ \\
Neutrophils & $1.40 \pm 0.11$ & $0.94 \pm 0.18^{*}$ & $1.01 \pm 0.27^{*}$ \\
Monocytes & $0.13 \pm 0.07$ & $0.09 \pm 0.04$ & $0.09 \pm 0.03$ \\
Eosinophils & $0.04 \pm 0.0$ & $0.02 \pm 0.01^{*}$ & $0.01 \pm 0.01^{*}$ \\
\hline
\end{tabular}

Cell counts expressed in $10^{3} / \mathrm{mm}^{3} ;{ }^{*} p<0.05$ versus vehicle.

2.8. Data Analysis. GI transit data was analyzed in Origin ${ }^{\circledR}$ and statistical moments were calculated in order to obtain the Mean Gastric Emptying Time (MGET), as the time $t$ (min) in which the average amount of magnetic material has been emptied from the stomach, weighted by the area under the emptying curve; the Mean Cecum Arrival Time (MCAT) defined as the time $t(\mathrm{~min})$ in which there was an increase in the average amount of magnetic meal that reached the cecum, weighted by the area under the curve between the arrival at the cecum and the cumulative maximum value; and the Mean Small Intestine Transit Time (MSITT) which was determined by the difference between MCAT and MGET $[15,20]$.

Gastric contractility signals were analyzed in Matlab by visual inspection and subsequently, Fast Fourier Transform (FFT) was applied. The highest peak of frequency for each FFT was determined as the gastric dominant frequency and the lowest was the intrinsic noise of the signal. Frequencies were expressed in hertz $(\mathrm{Hz})$ and then converted to cycles per minute (cpm). Amplitude of contraction was determined by the ratio between the intensity of gastric peak $(P)$ and noise peak intensity $\left(P^{\prime}\right)$ and expressed in decibels $(\mathrm{dB})$ as follows: $A=10 \log 10\left(P / P^{\prime}\right)[21]$.

2.9. Statistical Analysis. All results were expressed as mean \pm standard deviation (SD) and analyzed by ANOVA, followed by Tukey. Pearson correlation coefficient $(R)$ was applied to evaluate the relationship between intestinal variables. Only coefficients above 0.80 were considered significant. Differences were considered significant at a $p$ value $<0.05$.

\section{Results}

The treatment with prednisone reduced the total leukocytes number and differential count compared with control (vehicle) group, confirming the immunosuppression in both doses, as expected (Table 1).

Treatment with prednisone, in both doses, has increased $(\sim 4.8 \mathrm{cpm})$ the frequency of gastric contractions compared with the vehicle $(4.4 \pm 0.4)$ (Figure $1(\mathrm{a}))$ whereas the amplitude of contraction showed nonsignificant changes between groups (Figure 1(b)). Animals treated with $2.5 \mathrm{mg} / \mathrm{Kg}$ of prednisone had accelerated gastric emptying compared with vehicle (Figure 1(c)). Cecum arrival time (Figure 1(d)) was not different among groups.

As shown in Figure 2, the treatment with $2.5 \mathrm{mg} / \mathrm{Kg}$ of prednisone slowed intestinal transit compared with vehicle. Regarding the mast cell analysis, the prednisone in both doses reduced the mucosal MC number. Also, there was a significant positive correlation between small intestinal transit time and MC from mucosa (above $R=0.8$ ) after prednisone treatment (Figure 2). In control conditions, there was no correlation between these parameters.

Muscular layers and crypt depth had no changes after prednisone treatment, while villus height decreases for both treated groups compared with the vehicle (Figure 3).

\section{Discussion}

Our results indicate that the short term use of prednisone modified the gastrointestinal function and the morphological structure. Increased frequency of gastric contraction, accelerated gastric emptying, slowed intestinal transit, and decreased number of mucosal mast cells and villus height were observed.

Gastric emptying is a limiting step in the absorption of orally administered drugs and nutrients [22]. In previous studies, we already showed a hastened gastric emptying in male rats treated with prednisone after intermediate dose [23]. As prednisone was able to decrease the villus height in duodenum, the association of both data suggests a change in gastrointestinal absorption which may compromise the uptake of essential nutrients [24] and also the bioavailability of drugs since intraluminal environment has a great influence on the performance of the dosage forms administered orally $[25,26]$.

As expected, there was a decrease in leukocytes and mucosal mast cell after prednisone treatments [27]. Studies have shown the glucocorticoids cause apoptosis of lymphocytes in rodents [28] and also reduced mast cells in lungs $[29,30]$. Prednisone-treated mice had reduction of the inflammatory response in allergic pulmonary inflammation followed by the decrease of mast cell influx to the mucosa [12]. However, the effects of prednisone on intestinal mast cells had not yet been documented.

Oral prednisone therapy results in relevant time- and dose-dependent toxicity in diverse systemic diseases [31] and it is related to several side effects. In healthy condition, these alterations may have no clinical relevance; but it can be relevant in sick, geriatric, or debilitated patients [32]. Under specific conditions, for example, in lupus, prednisone has been consistently associated with increased irreversible damage and increasing rate of morbidity and mortality $[31,33]$. Several studies have demonstrated adverse gastrointestinal effects after short term administration of high 


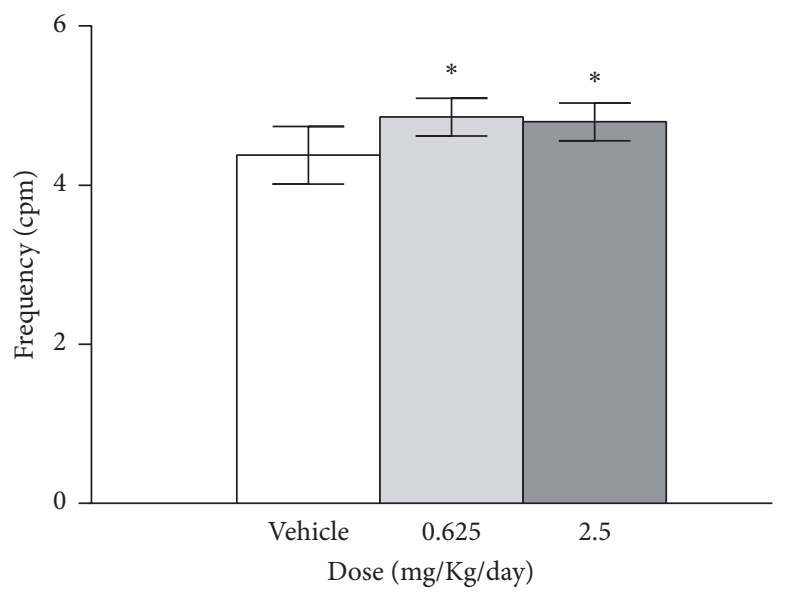

(a)

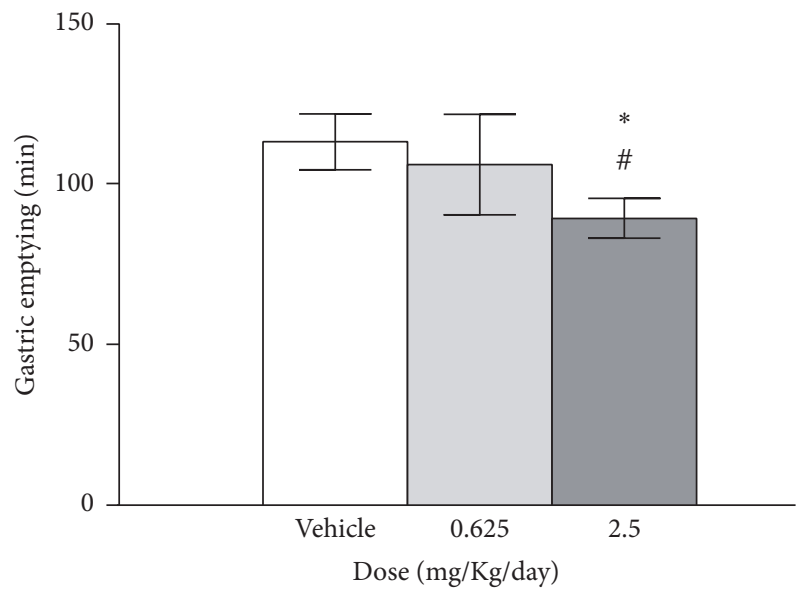

(c)

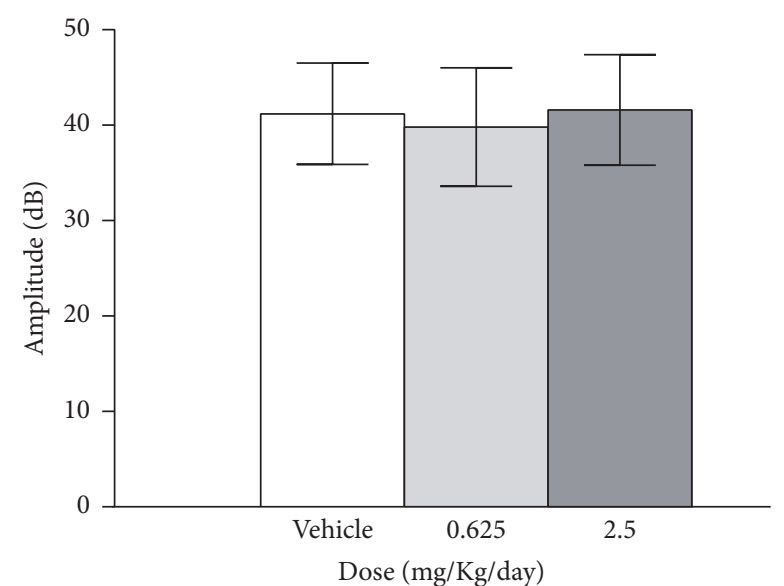

(b)

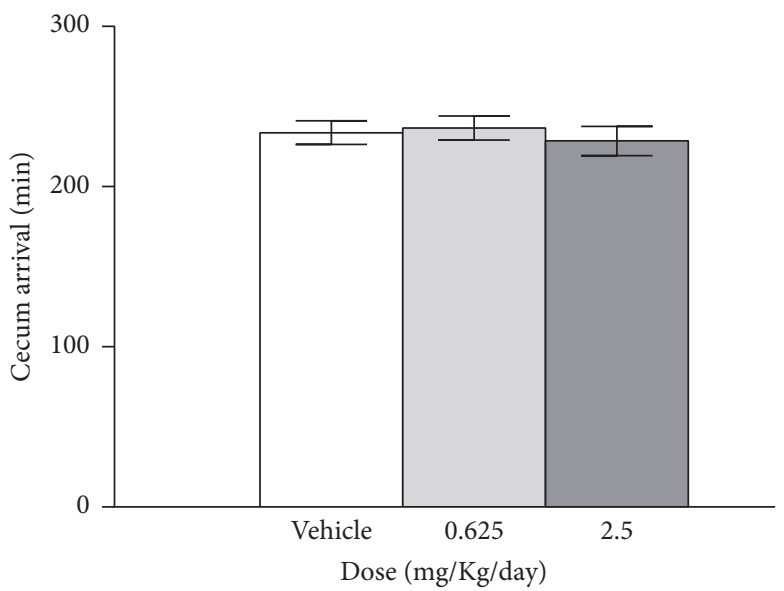

(d)

Figure 1: Frequency of gastric contractions (a), amplitude of contractions (b), gastric emptying (c), and cecum arrival (d) were determined for all groups. For comparison between groups: ${ }^{*} p<0.05$ versus vehicle; ${ }^{*} p<0.05$ versus $0.625 \mathrm{mg}$.

doses of methylprednisolone and dexamethasone $[32,34-$ 36]. Nevertheless, clinical trials comparing high $(>30 \mathrm{mg}$ and up to $100 \mathrm{mg}$ per day) versus low ( $\leq 7.5 \mathrm{mg} /$ day) or equivalent doses of prednisone are scant [31].

Quantification of adverse effects related to doses of glucocorticoids is still challenging, especially considering patients rarely receiving glucocorticoids as monotherapy [33]. The use of prednisone associated with other drugs complicates the assessment of their individual effects, since synergistic and/or antagonistic drug interactions can occur allowing prednisone to be considered harmless [37]. Doses $<7.5 \mathrm{mg}$ of prednisone daily seem to minimize adverse effects, but the dose below which treatment can be considered safe has not been defined [31]. However, even low doses of glucocorticoids (e.g., as high as $6 \mathrm{mg} / \mathrm{day}$ ) can be associated with organ damage $[33,38]$.

Studies focusing on the effects of prednisone on gastrointestinal motility and the relationship to the local immunity are limited $[39,40]$. Our study showed a strong positive correlation between intestinal transit time and the number of mucosal mast cells after prednisone treatment at both doses (Figure 2). Positive correlation between the number of mucosal mast cells and intestinal permeability in patients with diarrhea-predominant irritable bowel syndrome was also observed by Lee and collaborators [41]. Mast cell activation in intestinal mucosa releases mediators such as histamine, chymase, and prostaglandin which regulate the permeability $[42,43]$ and the protection maintained by the integrity of luminal epithelial barrier [44].

Besides regulation of the permeability, the enteric nervous system and cytokines such as IL-4 and IL-13 appear to be involved in the relationship between the number of mast cells and motor activity [10, 45]. Mast cells can be found in close spatial contact with interstitial cells of Cajal (ICC); however, studies focused on their distribution in rodent intestinal muscularis externa and association with motor function are lacking [46]. Propulsion of intestinal contents needs to be at an optimum rate to prevent complications arising from stasis, such as intestinal bacterial overgrowth [47]. Intestinal dysmotility can be associated with nausea and vomiting, bloating, or even visible distension $[48,49]$.

The evaluation of gastrointestinal transit time, gastric emptying, and contractility is fundamental to understand the 


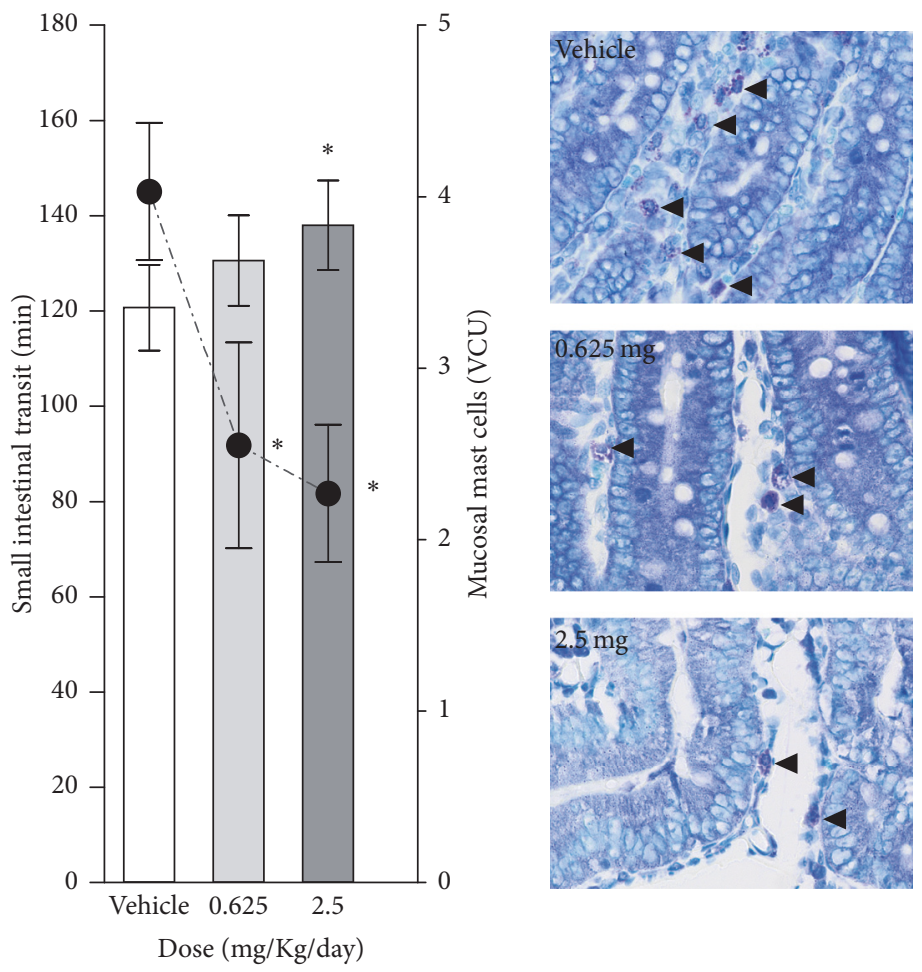

FIGURE 2: Small intestinal transit, mucosal mast cell, and correlation between them were determined for all groups. Arrows indicate mucosal mast cell in the histological examples. For comparison between groups: ${ }^{*} p<0.05$ versus vehicle.

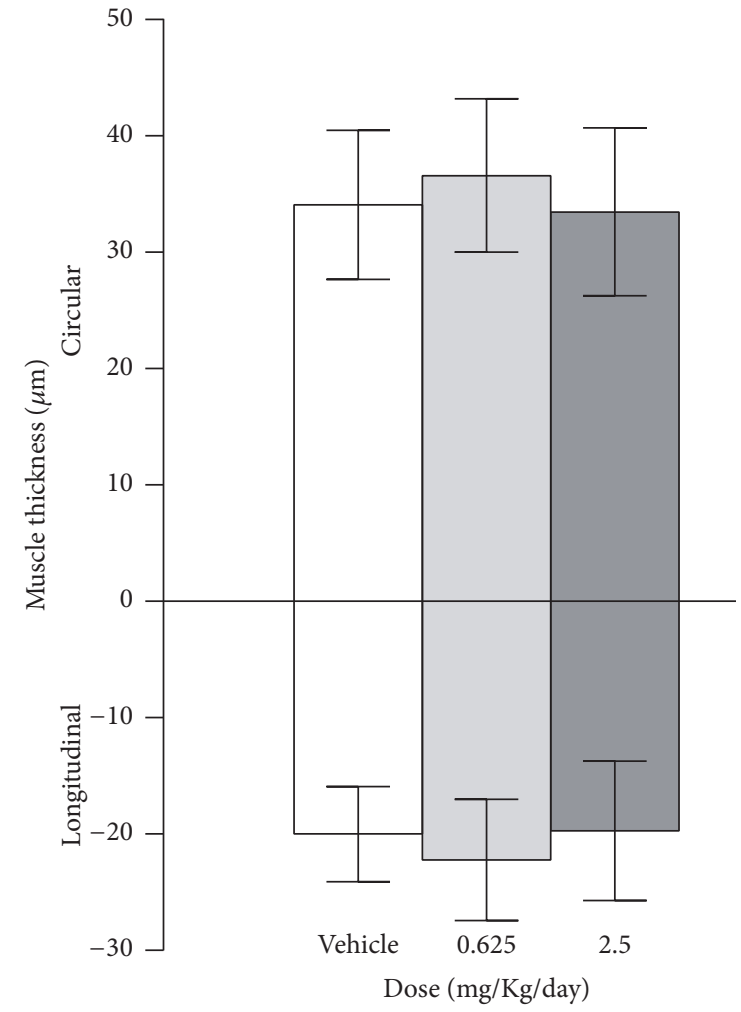

(a)

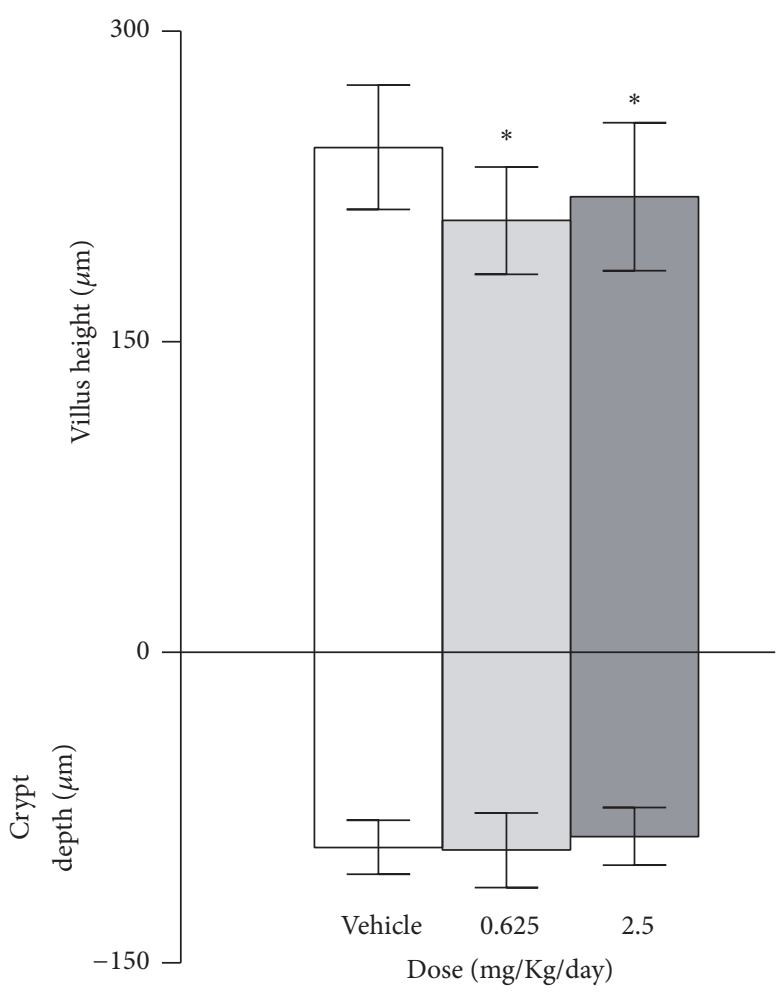

(b)

FIGURE 3: Muscle thickness (longitudinal and circular) (a) and villus height and crypt depth (b) were calculated for all groups. For comparison between groups: ${ }^{*} p<0.05$ versus vehicle. 
effect of drugs and the interaction with the gastrointestinal tract. Strain-gauge (SG) transducers implanted in laboratory animals and manometric tubes employed in several species, including humans, are often used. Nevertheless, both are invasive approaches, requiring surgery and uncomfortable catheter insertion, respectively [50]. Manometry records only pressure waves that occlude the lumen and, unlike SG, is unable to detect all contractions [13]. On the other hand, $\mathrm{ACB}$ allows evaluating GI transit in vivo embracing all the interference of gut hormone levels and, most importantly, on an intact enteric nervous system and gastrointestinal mucosal immunity.

\section{Conclusion}

Prednisone administered to rats increased the frequency of gastric contractions, hastened gastric emptying, slowed small intestinal transit, reduced mucosal mast cells, and decreased villus height. These findings indicate an impairment of intestinal absorption which may be linked to several GI dysfunctions and, thereafter, symptoms, which need to be clarified since prednisone is one of the most prescribed glucocorticoids worldwide. Noninvasive techniques such as ACB are promising tools towards evaluating the side effects of time course treatments on GI motility.

\section{Conflicts of Interest}

The authors declare that they have no conflicts of interest.

\section{Authors' Contributions}

Maysa Bruno de Lima participated in acquisition, analysis, and interpretation of data for the work and drafting the work for important intellectual content. Loyane Almeida Gama participated in acquisition, analysis, and interpretation of data for the work and drafting the work and revising it critically for important intellectual content. Andrieli Taise Hauschildt participated in analysis and interpretation of data for the work and drafting the work and revising it critically for important intellectual content. Denize Jussara Rupolo Dall'Agnol participated in analysis and interpretation of data for the work and drafting the work and revising it critically for important intellectual content. Luciana Aparecida Corá participated in conception of the work and revising it critically for important intellectual content. Madileine Francely Americo participated in conception of the work; analysis and interpretation of data for the work; and revising it critically for important intellectual content. Maysa Bruno de Lima and Loyane Almeida Gama contributed equally to this work. All authors approved the final version of the manuscript and agree to be accountable for all aspects of the work in ensuring that questions related to the accuracy or integrity of any part of the work are appropriately investigated and resolved.

\section{Acknowledgments}

The authors are grateful to Brazilian agencies FAPEMAT, CAPES, and CNPq for the partial financial support.

\section{References}

[1] S. Ramamoorthy and J. A. Cidlowski, "Corticosteroids. Mechanisms of Action in Health and Disease," Rheumatic Disease Clinics of North America, vol. 42, no. 1, pp. 15-31, 2016.

[2] L. Fardet, I. Petersen, and I. Nazareth, "Prevalence of longterm oral glucocorticoid prescriptions in the UK over the past 20 years.," Rheumatology (Oxford, England), vol. 50, no. 11, pp. 1982-1990, 2011.

[3] R. A. Overman, J.-Y. Yeh, and C. L. Deal, "Prevalence of oral glucocorticoid usage in the United States: A general population perspective," Arthritis Care and Research, vol. 65, no. 2, pp. 294298, 2013.

[4] L. Fardet, I. Petersen, and I. Nazareth, "Common infections in patients prescribed systemic glucocorticoids in primary care: a population-based cohort study," PLoS Medicine, vol. 13, no. 5, Article ID e1002024, 2016.

[5] T. K. Bergmann, K. A. Barraclough, K. J. Lee, and C. E. Staatz, "Clinical pharmacokinetics and pharmacodynamics of prednisolone and prednisone in solid organ transplantation," Clinical Pharmacokinetics, vol. 51, no. 11, pp. 711-741, 2012.

[6] A. K. Waljee, M. A. Rogers, P. Lin et al., "Short term use of oral corticosteroids and related harms among adults in the United States: population based cohort study," British Medical Journal, 357, article j1415.

[7] L. A. Corá, M. F. Américo, R. B. Oliveira et al., "Biomagnetic methods: Technologies applied to pharmaceutical research," Pharmaceutical Research, vol. 28, no. 3, pp. 438-455, 2011.

[8] G. Triadafilopoulos, "Glucocorticoid therapy for gastrointestinal diseases," Expert Opinion on Drug Safety, vol. 13, no. 5, pp. 563-572, 2014.

[9] G. E. Boeckxstaens and M. M. Wouters, "Neuroimmune factors in functional gastrointestinal disorders: A focus on irritable bowel syndrome," Neurogastroenterology and Motility, pp. 1-10, 2016.

[10] S. C. Bischoff, "Physiological and pathophysiological functions of intestinal mast cells," Seminars in Immunopathology, vol. 31, no. 2, pp. 185-205, 2009.

[11] G. Barbara, V. Stanghellini, R. de Giorgio, and R. Corinaldesi, "Functional gastrointestinal disorders and mast cells: implications for therapy," Neurogastroenterology and Motility, vol. 18, no. 1, pp. 6-17, 2006.

[12] L. G. Bankova, D. F. Dwyer, A. Y. Liu, K. F. Austen, and M. F. Gurish, "Maturation of mast cell progenitors to mucosal mast cells during allergic pulmonary inflammation in mice," Mucosal Immunology, vol. 8, no. 3, pp. 596-606, 2015.

[13] M. F. Américo, R. G. Marques, E. A. Zandoná et al., "Validation of ACB in vitro and in vivo as a biomagnetic method for measuring stomach contraction," Neurogastroenterology and Motility, vol. 22, no. 12, pp. 1340-e374, 2010.

[14] C. C. Quini, M. F. Américo, L. A. Corá et al., "Employment of a noninvasive magnetic method for evaluation of gastrointestinal transit in rats," Journal of Biological Engineering, vol. 6, article no. $6,2012$.

[15] L. A. Corá, F. G. Romeiro, M. Stelzer et al., "AC biosusceptometry in the study of drug delivery," Advanced Drug Delivery Reviews, vol. 57, no. 8, pp. 1223-1241, 2005.

[16] M. M. Wouters, M. Vicario, and J. Santos, "The role of mast cells in functional GI disorders," Gut, vol. 65, no. 1, pp. 155-168, 2016.

[17] J. R. D. Lemos, W. F. Rodrigues, C. B. Miguel et al., "Influence of Parasite Load on Renal Function in Mice Acutely Infected with 
Trypanosoma cruzi," PLoS ONE, vol. 8, no. 8, Article ID e71772, 2013.

[18] H. R. Miller and W. F. Jarrett, "Immune reactions in mucous membranes. I. Intestinal mast cell response during helminth expulsion in the rat." Immunology, vol. 20, no. 3, pp. 277-288, 1971.

[19] M. de Oliveira Belém, C. P. Cirilo, A. P. de Santi-Rampazzo et al., "Intestinal morphology adjustments caused by dietary restriction improves the nutritional status during the aging process of rats," Experimental Gerontology, vol. 69, pp. 85-93, 2015.

[20] F. Podczeck, J. M. Newton, and K.-H. Yuen, “The description of the gastrointestinal transit of pellets assessed by gamma scintigraphy using statistical moments," Pharmaceutical Research, vol. 12, no. 3, pp. 376-379, 1995.

[21] T. S. Chen, M. L. Doong, F. Y. Chang, S. D. Lee, and P. S. Wang, "Effects of sex steroid hormones on gastric emptying and gastrointestinal transit in rats," American Journal of Physiology Gastrointestinal and Liver Physiology, vol. 268, pp. 171-176, 1995.

[22] N. L. Yanchar, R. N. Fedorak, N. M. Kneteman, and D. L. Sigalet, "Nutritional and intestinal effects of the novel immunosuppressive agents: Deoxyspergualin, rapamycin, and mycophenolate mofetil," Clinical Biochemistry, vol. 29, no. 4, pp. 363-369, 1996.

[23] D. J. R. Dall'Agnol, A. T. Hauschildt, M. B. Lima, L. A. Corá, M. C. B. Teixeira, and M. F. Américo, "Effects of immunosuppressive drugs on gastrointestinal transit of rats: Effects of tacrolimus, cyclosporine, and prednisone," Transplantation Proceedings, vol. 46, no. 6, pp. 1872-1874, 2014.

[24] K. Yamamoto, E. Shuang, H. Yu, S. Yu, and T. Tsuduki, "Highfat diet intake from senescence inhibits the attenuation of cell functions and the degeneration of villi with aging in the small intestine, and inhibits the attenuation of lipid absorption ability in SAMP8 mice," Journal of Clinical Biochemistry and Nutrition, vol. 57, no. 3, pp. 204-211, 2015.

[25] E. L. McConnell, H. M. Fadda, and A. W. Basit, "Gut instincts: explorations in intestinal physiology and drug delivery," International Journal of Pharmaceutics, vol. 364, no. 2, pp. 213-226, 2008.

[26] F. J. O. Varum, G. B. Hatton, and A. W. Basit, "Food, physiology and drug delivery," International Journal of Pharmaceutics, vol. 457, no. 2, pp. 446-460, 2013.

[27] Y. Hirotani, K. Mikajiri, K. Ikeda, M. Myotoku, and N. Kurokawa, "Changes of the peptide YY levels in the intestinal tissue of rats with experimental colitis following oral administration of mesalazine and prednisolone," Yakugaku Zasshi, vol. 128, no. 9, pp. 1347-1353, 2008.

[28] Z. Yao, D. C. Dubois, R. R. Almon, and W. J. Jusko, "Pharmacokinetic/pharmacodynamic modeling of corticosterone suppression and lymphocytopenia by methylprednisolone in rats," Journal of Pharmaceutical Sciences, vol. 97, no. 7, pp. 2820-2832, 2008.

[29] A. M. Bentley, Q. Hamid, D. S. Robinson et al., "Prednisolone Treatment in Asthma: Reduction in the Numbers of Eosinophils, T Cells, Tryptase-only Positive Mast Cells, and Modulation of IL-4, IL-5, and Interferon-gamma Cytokine Gene Expression within the Bronchial Mucosa," American Journal of Respiratory and Critical Care Medicine, vol. 153, no. 2, pp. 551-556, 1996.

[30] A. James, P. Gyllfors, E. Henriksson et al., "Corticosteroid treatment selectively decreases mast cells in the smooth muscle and epithelium of asthmatic bronchi," Allergy: European Journal of Allergy and Clinical Immunology, vol. 67, no. 7, pp. 958-961, 2012.

[31] G. Ruiz-Irastorza, A. Danza, and M. Khamashta, "Glucocorticoid use and abuse in SLE," Rheumatology, vol. 51, no. 7, pp. 1145-1153, 2012.

[32] A. H. Graham and M. S. Leib, "Effects of prednisone alone or prednisone with ultralow-dose aspirin on the gastroduodenal mucosa of healthy dogs," Journal of Veterinary Internal Medicine, vol. 23, no. 3, pp. 482-487, 2009.

[33] S. Sciascia, E. Mompean, M. Radin, D. Roccatello, and M. J. Cuadrado, "Rate of adverse effects of medium- to highdose glucocorticoid therapy in systemic lupus erythematosus: a systematic review of randomized control trials," Clinical Drug Investigation, pp. 1-6, 2017.

[34] S. W. Dow, R. A. Rosychuk, A. E. McChesney, and C. R. Curtis, "Effects of flunixin and flunixin plus prednisone on the gastrointestinal tract of dogs.," American journal of veterinary research, vol. 51, no. 7, pp. 1131-1138, 1990.

[35] S. E. Boston, N. M. M. Moens, S. A. Kruth, and E. P. Southorn, "Endoscopic evaluation of the gastroduodenal mucosa to determine the safety of short-term concurrent administration of meloxicam and dexamethasone in healthy dogs," American Journal of Veterinary Research, vol. 64, no. 11, pp. 1369-1375, 2003.

[36] C. R. Rohrer, R. C. Hill, A. Fischer et al., "Gastric hemorrhage in dogs given high doses of methylprednisolone sodium succinate," American Journal of Veterinary Research, vol. 60, no. 8, pp. 977-981, 1999.

[37] R. B. Waade, E. Molden, H. Refsum, and M. Hermann, "Serum concentrations of antidepressants in the elderly," Therapeutic Drug Monitoring, vol. 34, no. 1, pp. 25-30, 2012.

[38] Z. A. Zahr, H. Fang, L. S. Magder, and M. Petri, "Predictors of corticosteroid tapering in SLE patients: The Hopkins Lupus Cohort," Lupus, vol. 22, no. 7, pp. 697-701, 2013.

[39] H. de Jonge and D. R. J. Kuypers, "Pharmacogenetics in solid organ transplantation: current status and future directions," Transplantation Reviews, vol. 22, no. 1, pp. 6-20, 2008.

[40] S. Hernández-Díaz and L. A. García Rodríguez, "Steroids and risk of upper gastrointestinal complications," American Journal of Epidemiology, vol. 153, no. 11, pp. 1089-1093, 2001.

[41] H. Lee, J. H. Park, D. I. Park et al., "Mucosal mast cell count is associated with intestinal permeability in patients with diarrhea predominant irritable bowel syndrome," Journal of Neurogastroenterology and Motility, vol. 19, no. 2, pp. 244-250, 2013.

[42] K. R. Groschwitz, R. Ahrens, H. Osterfeld et al., "Mast cells regulate homeostatic intestinal epithelial migration and barrier function by a chymase/Mcpt4-dependent mechanism," Proceedings of the National Academy of Sciences of the United States of America, vol. 106, no. 52, pp. 22381-22386, 2009.

[43] J. Santos, P.-C. Yang, J. D. Söderholm, M. Benjamin, and M. H. Perdue, "Role of mast cells in chronic stress induced colonic epithelial barrier dysfunction in the rat," Gut, vol. 48, no. 5, pp. 630-636, 2001.

[44] J. R. Turner, "Intestinal mucosal barrier function in health and disease," Nature Reviews Immunology, vol. 9, no. 11, pp. 799-809, 2009.

[45] L. L. Reber, R. Sibilano, K. Mukai, and S. J. Galli, "Potential effector and immunoregulatory functions of mast cells in mucosal immunity," Mucosal Immunology, vol. 8, no. 3, pp. 444463, 2015. 
[46] H. B. Mikkelsen, "Interstitial cells of Cajal, macrophages and mast cells in the gut musculature: morphology, distribution, spatial and possible functional interactions," Journal of Cellular and Molecular Medicine, vol. 14, no. 4, pp. 818-832, 2010.

[47] F. Castiglione, G. Del Vecchio Blanco, A. Rispo et al., "Orocecal transit time and bacterial overgrowth in patients with Crohn's disease," Journal of Clinical Gastroenterology, vol. 31, no. 1, pp. 63-66, 2000.

[48] S. S. C. Rao, M. Camilleri, W. L. Hasler et al., "Evaluation of gastrointestinal transit in clinical practice: position paper of the American and European Neurogastroenterology and Motility Societies," Neurogastroenterology and Motility, vol. 23, no. 1, pp. 8-23, 2011.

[49] M. Fischer, S. Siva, J. M. Wo, and H. M. Fadda, "Assessment of Small Intestinal Transit Times in Ulcerative Colitis and Crohn's Disease Patients with Different Disease Activity Using Video Capsule Endoscopy," AAPS PharmSciTech, vol. 18, no. 2, pp. 404-409, 2017.

[50] J. M. Froehlich, M. A. Patak, C. Von Weymarn, C. F. Juli, C. L. Zollikofer, and K.-U. Wentz, "Small bowel motility assessment with magnetic resonance imaging," Journal of Magnetic Resonance Imaging, vol. 21, no. 4, pp. 370-375, 2005. 


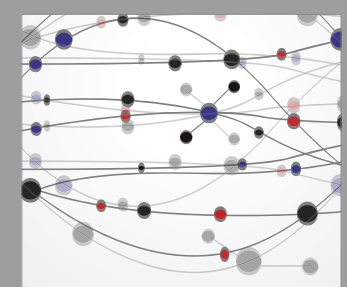

The Scientific World Journal
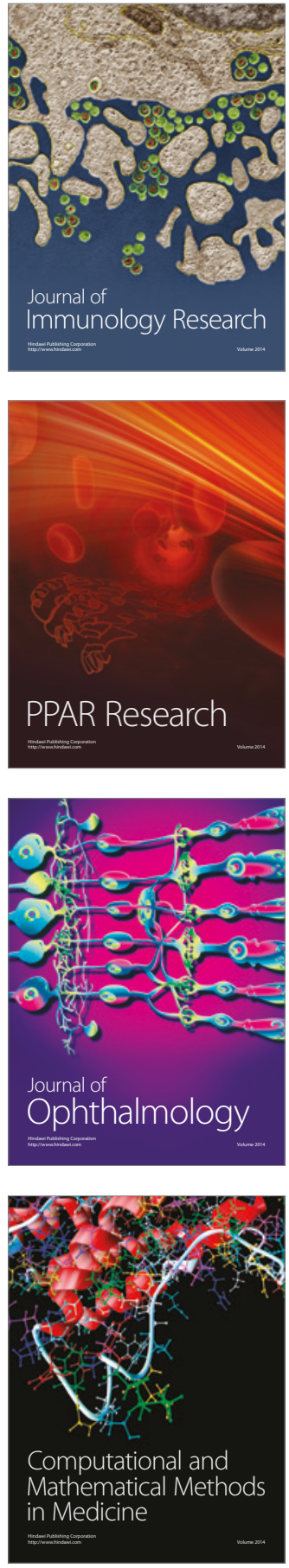

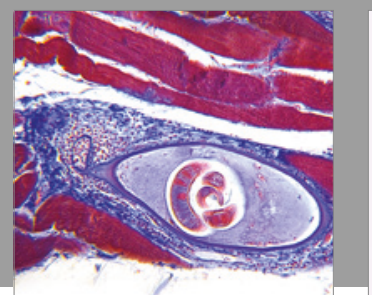

Gastroenterology Research and Practice
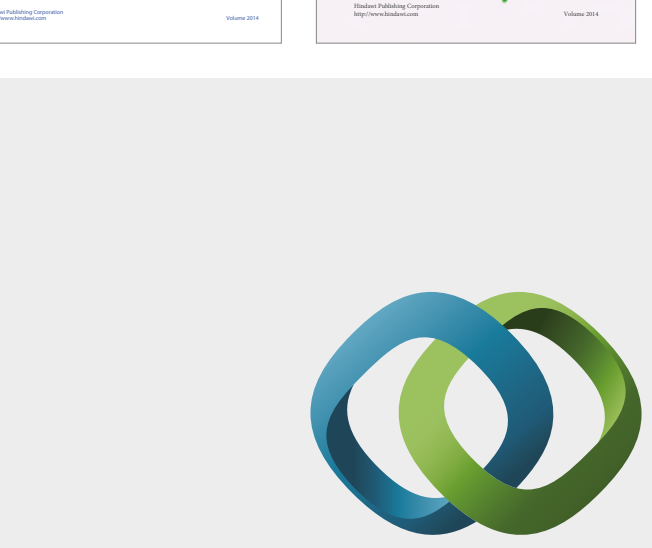

\section{Hindawi}

Submit your manuscripts at

https://www.hindawi.com
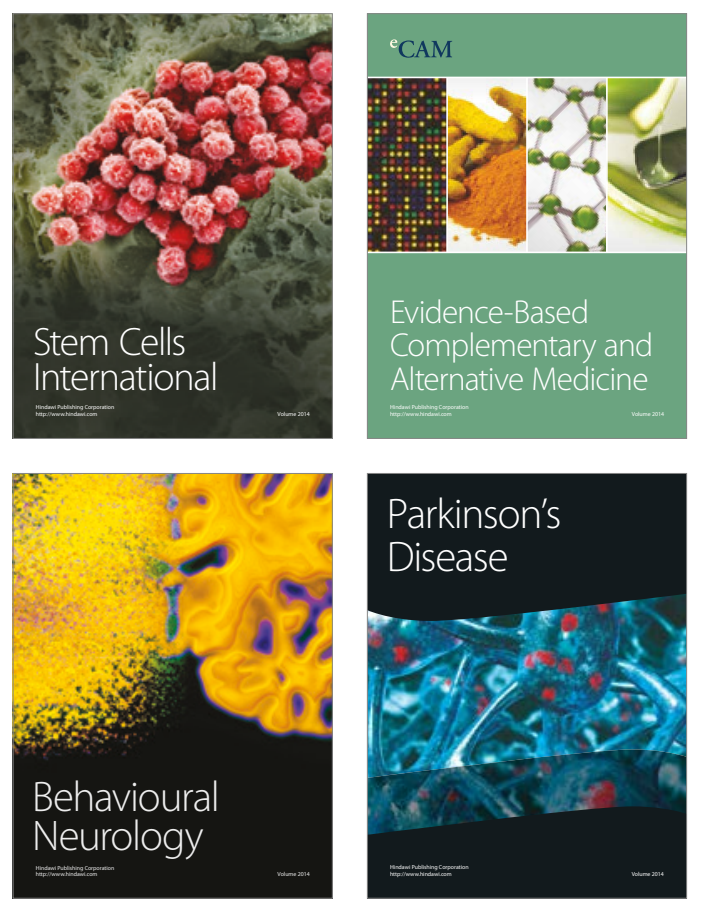
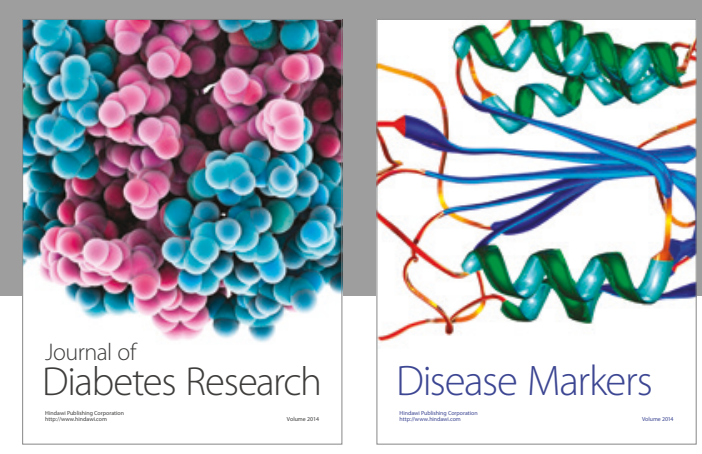

Disease Markers
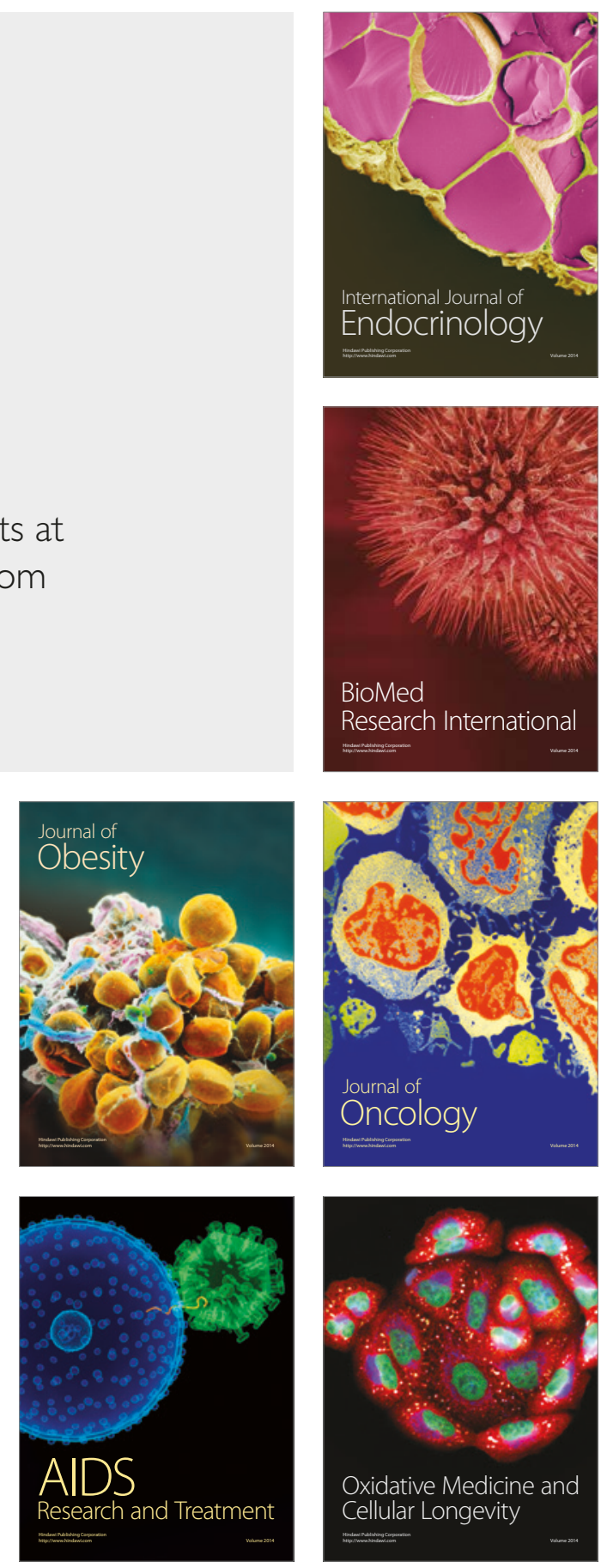